\title{
Regional block anesthesia in a patient with factor $V$ Leiden mutation and axillary artery occlusion
}

\author{
This article was published in the following Dove Press journal: \\ Local and Regional Anesthesia \\ I5 February 201I \\ Number of times this article has been viewed
}

\section{Kerem Erkalp' \\ Mevlut Comlekci' \\ Bekir Inan² \\ Gokcen Basaranoglu' \\ Haluk Ozdemir ${ }^{1}$ \\ Leyla Saidoglu'}

'Department of Anaesthesiology and Reanimation, Vakif Gureba Hospital, Istanbul, Turkey; ${ }^{2}$ Department of Vascular Surgery, Vakif Gureba Hospital, Istanbul, Turkey
Correspondence: Kerem Erkalp Șenlikköy Mah. Ekșinar Cad. İncir Sok. Sarı Konaklar Sitesi, No:3, B-Blok, Daire:6, Florya, Bakırköy, Istanbul, Turkey

Tel +902125346900

Fax +902126217580

Email keremerkalp@hotmail.com

\begin{abstract}
Anesthetic management of patients with coagulation disorders presents safety and technical challenges. This case describes a 58-year-old woman with factor V Leiden mutation who required distal saphenous vein harvest and axillo-brachial bypass to treat axillary artery occlusion. The patient underwent surgery with satisfactory anesthesia using infraclavicular brachial plexus block, thoracic paravertebral block, and unilateral subarachnoid block. These three regional anesthetic interventions were performed in lieu of general anesthesia to minimize risks of thrombotic events, pain, and to decrease recovery time. Despite higher failure rates of regional anesthesia, longer time required for procedures, and added discomforts during surgery, the benefits may outweigh risks for selected high-risk patients, including those with factor V Leiden mutations.
\end{abstract}

Keywords: regional anesthesia, factor V Leiden, pain, vein harvest

\section{Introduction}

High-risk vascular surgery patients, including those with thrombotic disorders, present safety and technical challenges for anesthetic management. Given the poor tolerance of these patients to hemodynamic perturbations, the safest methods should be considered for surgical anesthesia. ${ }^{1}$ The factor V Leiden (FVL) mutation, a single point mutation that confers factor $\mathrm{V}$ resistance to protein $\mathrm{C}$ degradation, is the most common genetic cause of thrombophilia. ${ }^{2}$ In this case report, we discuss the successful use of infraclavicular brachial plexus, thoracic paravertebral, and unilateral subarachnoid blocks for a patient with FVL mutation and left axillary artery occlusion.

\section{Case report}

A 58-year-old, $76 \mathrm{~kg}, 162 \mathrm{~cm}$ tall, American Society of Anesthesiologists (ASA) physical status II woman was scheduled for axillo-brachial bypass to treat left axillary artery occlusion (subclavian steal syndrome). The surgeon planned to harvest the patient's left distal saphenous vein for axillo-brachial bypass. The patient had a history of hypertension, chronic obstructive pulmonary disease (COPD) (FEV $/$ FVC [ forced expiratory volume in 1 second/forced vital capacity] ratio: $50 \%$ by spirometry) and FVL mutation. Her medications included valsartan $160 \mathrm{mg}$ plus hydrochlorothiazide $25 \mathrm{mg}$ daily, aspirin $300 \mathrm{mg}$ daily, formoterol $12 \mu \mathrm{g}$ plus budesonide $400 \mu \mathrm{g}$ inhaled twice daily, tiotropium bromide $18 \mu \mathrm{g}$ inhaled daily, and theophylline $200 \mathrm{mg}$ twice daily. Pre-operative platelet count, bleeding time, prothrombin time, activated partial thromboplastin time (aPTT), and international normalized ratio (INR) were normal. 
Past medical history included an abdominal hysterectomy and a laparoscopic cholesystectomy.

The anesthesia plan was explained to the patient, who provided written informed consent. Low molecular weight heparin (LMWH) 40 mg was administered subcutaneously 12 hours before the procedure, and her daily COPD medications (formoterol/budesonide inhaler, tiotropium inhaler, and theophylline) were given on the morning of the procedure. After applying electrocardiography, noninvasive arterial blood pressure, and pulse oximetry monitors, the patient was placed in the sitting position and oxygen was applied via face mask at a rate of $2 \mathrm{~L}$ per minute. The patient was not premedicated. She was given midazolam $1 \mathrm{mg}$ and fentanyl $25 \mu \mathrm{g}$ for sedation, and $500 \mathrm{~mL}$ of crystalloid solution intravenously.

The thoracic paravertebral block (TPVB) was performed according to the method of Eason and Wyatt. ${ }^{3}$ Palpation was used to localize the seventh cervical vertebra (C7) and first thoracic vertebra (T1) at the tip of the scapula. Spinous processes of T1 through T5 were outlined, and a point was marked $2.5 \mathrm{~cm}$ left lateral to each of the spinous processes (Figure 1). A vertical line was drawn to connect these points. The back was cleaned by a sterile technique using povidone-iodine. Skin and subcutaneous tissue were

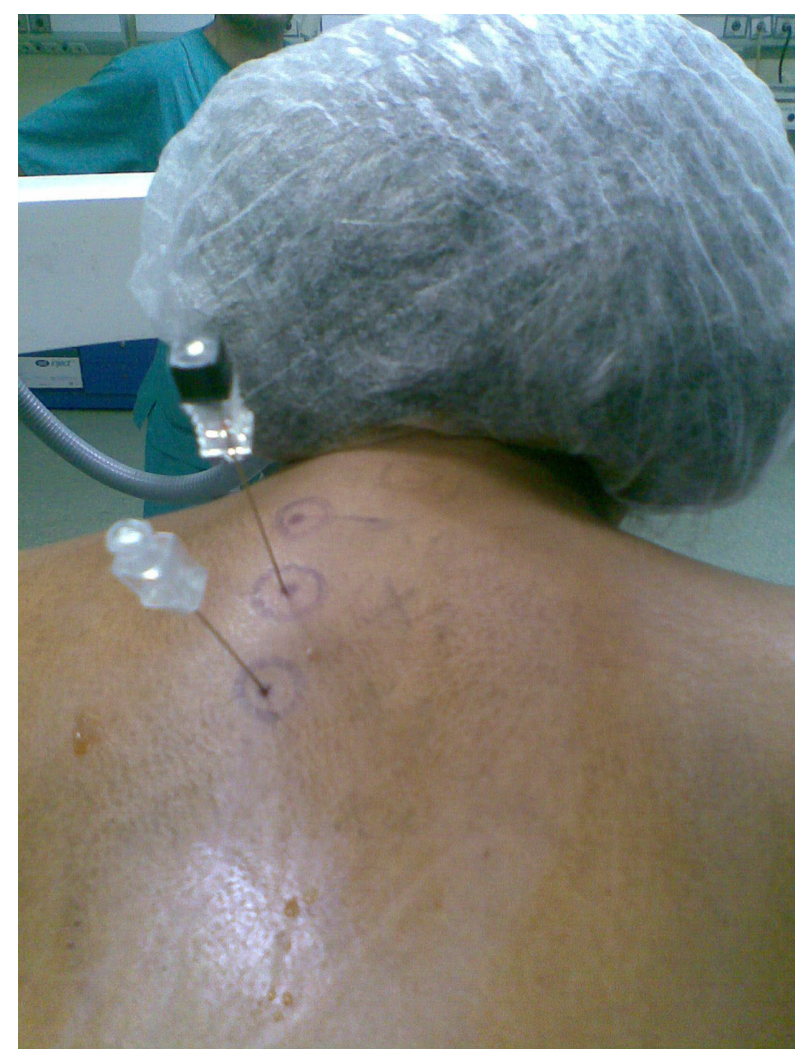

Figure I Thoracic paravertebral block at T1, T2, and T3 levels. anesthetized along the vertical line with $4 \mathrm{~mL}$ lidocaine $1 \%$. A 22-gauge spinal needle was inserted $2.5 \mathrm{~cm}$ lateral to the spinous process of $\mathrm{T} 1$, in the direction of $\mathrm{T} 1$. The transverse process was found with the tip of the needle, and then the needle was withdrawn to the skin and redirected caudally to slide under the transverse process. The needle was advanced to the paravertebral space, as identified by loss of resistance to air. After the paravertebral space was identified and aspiration did not produce blood, air, or cerebrospinal fluid, $5 \mathrm{~mL}$ of levobupivacaine was injected, and the needle was removed. This was repeated at levels T2 and T3 (Figure 1). The patient was placed supine and observed for signs of intravascular or epidural injection and respiratory difficulty. No complications were noted. Sensation was assessed by using ice-cold and pin-prick tests, repeated at 5-minute intervals. These tests showed anesthesia that extended from T1 through T3 on the left hemithorax.

After TPVB, we performed a left infraclavicular brachial plexus block. We used Comlekci et al's technique for infraclavicular block, in which the highest point of the shoulder is taken as a reference point. ${ }^{4}$ The infraclavicular region was prepared with povidone-iodine. Using a 22-gauge, $100 \mathrm{~mm}$ insulated needle and a nerve stimulator (StimuplexB ${ }^{\circledR}$, Braun AG, Melsungen, Germany), we assessed hand responses for $\mathrm{n}$. medianus and $\mathrm{n}$. musculocutaneous at $0.4 \mathrm{~mA}$. A total of $200 \mathrm{mg}$ lidocaine $2 \%$ $(10 \mathrm{~mL})$ and $150 \mathrm{mg}$ levobupivacain $0.5 \%(30 \mathrm{~mL})$ was injected slowly with aspirations after every $5 \mathrm{~mL}$ (Figure 2). Repeated sensory blockade assessments were performed at frequent intervals.

Ten minutes after completing the TPVB, unilateral spinal block was performed in the leftdown lateral decubitis position. Spinal block was accomplished with a midline approach under aseptic conditions. A 25-gauge Quincke needle was used to introduce $5 \mathrm{mg}$ of hyperbaric bupivacaine $0.5 \%$ for induction at the L3-L4 interspace. The sensorial block reached the $\mathrm{L} 2$ level after 15 minutes. The patient was positioned supine and the procedure begun. Two surgical teams worked simultaneously. One team harvested the distal saphenous vein while the other explored the bypass area. The left distal saphenous vein was prepared in 15 minutes and the area closed primarily. Left axillo-brachial bypass was performed in 150 minutes.

The patient recovered from brachial and thoracic paravertebral block in 4 hours and spinal block in 2 hours. The pain-free period after the procedure was 7 hours at the axillary artery site and 4 hours at the saphenous vein harvest site. Oral medications were started on the second postoperative 


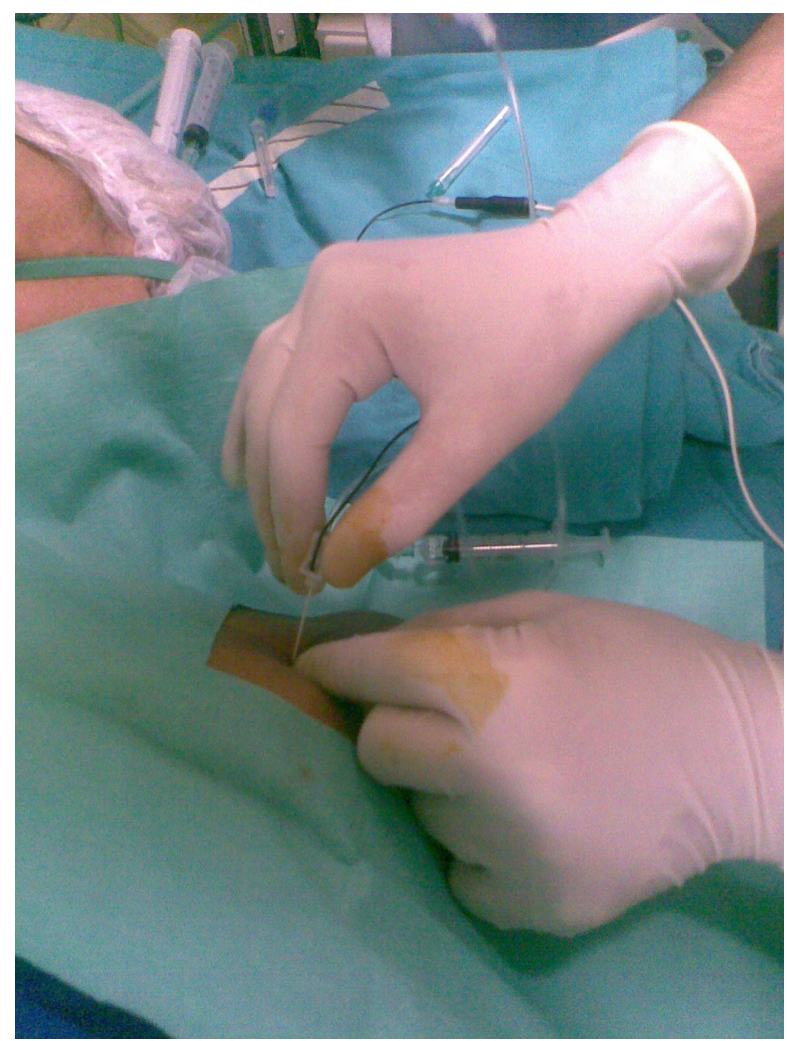

Figure 2 Left infraclavicular brachial plexus block.

day, and the patient was discharged on postoperative day 7 without complications.

\section{Discussion}

Inherited resistance to activated protein C through FVL mutation leads to a thrombophilic state. ${ }^{5} \mathrm{FVL}$ mutation is the most common inherited risk factor for venous thromboembolism, with heterozygous carriers having a 4-10-fold increased risk of deep vein thrombosis (DVT) and homozygous patients having up to a 100 -fold increase in DVT risk. ${ }^{6}$

While planning the patient's anesthesia management, we searched for methods associated with quick recovery, less postoperative pain, less postoperative nausea and vomiting, reduced postoperative analgesic requirements, reduced association with thromboembolic events, and shorter hospital stays. Because of the patient's advanced obstructive lung disease, we chose regional anesthesia. This approach was also chosen in this patient with an FVL mutation because regional anesthesia is associated with a lower risk of thrombosis compared to general anesthesia. ${ }^{7}$

Although we chose an infraclavicular block for arm anesthesia, we performed sensorial blockade of the axillary region using a TPVB at the T1, T2, and T3 levels. ${ }^{8}$ TPVB can be performed with the patient sitting, lying on the side, or prone. We chose the sitting position because it provides easy identification of landmarks. ${ }^{9}$ We believed that unilateral low-dose spinal anesthesia would be sufficient for saphenous vein harvest. Hyperbaric bupivacaine at $4 \mathrm{mg}$ and $6 \mathrm{mg}$ doses have been compared and found to be equivalent for unilateral, segmental spinal anesthesia for outpatient knee arthroscopy. The $4 \mathrm{mg}$ dose appears superior to the $6 \mathrm{mg}$ dose because it produces faster spinal anesthesia induction and the patient achieves discharge criteria significantly earlier. ${ }^{10}$ We used $5 \mathrm{mg}$ of hyperbaric bupivacaine, which proved adequate during saphenous vein harvest.

For most patients, LMWH thromboprophylaxis should be discontinued 10-12 hours prior to surgery and coagulation status (aPTT) should be assessed prior to neuraxial blockade. ${ }^{11}$ Although our patient was prone to thrombosis because of her FVL mutation, we discontinued LMWH, as per general recommendations, 12 hours prior to the procedure.

Performing a combination of regional techniques on one patient is time consuming, may create intraoperative patient discomfort, and may be associated with higher failure rates. These factors may also contribute to an increased risk of technique-specific complications and local anesthetic toxicity. ${ }^{12}$ However, these regional techniques may be suitable alternatives for patients with thrombophilias, because they may be performed with minimal postoperative pain and early recovery without thromboembolic complications.

\section{Disclosure}

The authors report no conflicts of interest in this work.

\section{References}

1. Basagan-Mogol E, Turker G, Yilmaz M, et al. Combination of a psoas compartment, sciatic nerve, and T12-L1 paravertebral blocks for femoropopliteal bypass surgery in a high-risk patient. $J$ Cardiothorac Vasc Anesth. 2008;22:337-339.

2. Harnett MJ, Walsh ME, McElrath TF, et al. The use of central neuraxial techniques in parturients with factor V Leiden mutation. Anesth Analg. 2005;101:1821-1823.

3. Eason MJ, Wyatt R. Paravertebral thoracic block-a reappraisal. Anaesthesia. 1979;34:638-642.

4. Comlekci M, Basaranoglu G, Suren M, et al. An approach to infraclavicular brachial plexus block: the highest point of the shoulder as a reference. Anesth Analg. 2006;103:1634-1635.

5. Curigliano G, Mandalà M, Sbanotto A, et al. Factor V leiden mutation in patients with breast cancer with a central venous catheter: risk of deep vein thrombosis. Support Cancer Ther. 2006;3:98-102.

6. Cooley BC, Chen CY, Schmeling G. Increased venous versus arterial thrombosis in the Factor V Leiden mouse. Thromb Res. 2007;119: $747-751$.

7. Hollmann MW, Wieczorek KS, Smart M, et al. Epidural anesthesia prevents hypercoagulation in patients undergoing major orthopedic surgery. Reg Anesth Pain Med. 2001;26:215-222.

8. Cooter RD, Rudkin GE, Gardiner SE. Day case breast augmentation under paravertebral blockade: a prospective study of 100 consecutive patients. Aesthetic Plast Surg. 2007;31:666-673. 
9. Karmakar MK. Thoracic paravertebral block. Anesthesiology. 2001;95: $771-780$.

10. Valanne JV, Korhonen AM, Jokela RM, et al. Selective spinal anesthesia: a comparison of hyperbaric bupivacaine $4 \mathrm{mg}$ versus $6 \mathrm{mg}$ for outpatient knee arthroscopy. Anesth Analg. 2001;93:1377-1379.

11. Horlocker TT, Wedel DJ, Benzon H, et al. Regional anesthesia in the anticoagulated patient: defining the risks (the second ASRA Consensus Conference on Neuraxial Anesthesia and Anticoagulation). Reg Anesth Pain Med. 2003;28:172-197.
12. Albani A, Renghi A, Gramaglia L, et al. Regional anaesthesia in vascular surgery: a multidisciplinary approach to accelerate recovery and postoperative discharge. Minerva Anestesiol. 2001;67:151-154.

\section{Publish your work in this journal}

Local and Regional Anesthesia is an international, peer-reviewed, open access journal publishing on the development, pharmacology, delivery and targeting and clinical use of local and regional anesthetics and analgesics. The journal welcomes submitted papers covering original research, basic science, clinical studies, reviews \& evaluations, guidelines, expert opinion and commentary, case reports and extended reports. The manuscript management system is completely online and includes a very quick and fair peer-review system, which is all easy to use. Visit http://www.dovepress.com/testimonials.php to read real quotes from published authors. 